\title{
A integração de imigrantes brasileiras em Roma: conquistas e dificuldades*
}

\section{Isabela Cabral Félix de Sousa**}

\author{
Introdução
}

A migração não é mais vista como processo linear, mas sim como uma complexa dinâmica de orientações transnacionais (MONKMAN, 1999; SCHILLER, BASCH \& BLANC-SZANTON, 1992). Isso porque algumas populações migrantes mantêm laços fortes e podem retornar tanto ocasionalmente quanto definitivamente aos seus países de origem.

Condições de vida dos imigrantes são muitas vezes comparadas com as da população do país de destino (ALI, 2002; BASSANEZI \& BOGUS, 1998; OGBU, 1987; PÉREZ, 2002). No entanto, essas comparações muitas vezes deixam de levar em conta as formas pelas quais os que migraram percebem tais condições.

O conjunto das mudanças econômicas, sociais e culturais vem afetando as relações de gênero, levando a um aumento da migração feminina, de maneira tal que em muitos casos esse contingente supera o masculino nas migrações. No caso específico da Itália, objeto deste estudo, trabalhos, como os de Bassanezi e Bogus (1998), citam dados oficiais do Centro Elaborazione Dati Ministero Dell Interno-Italia (Ministério do Interno da Itália) que demonstravam que, em 1995, do total de imigrantes brasileiros $70 \%$ eram mulheres. Portanto, é necessário elaborar uma perspectiva que

\footnotetext{
* Agradeço imensamente as pessoas que foram entrevistadas cedendo depoimentos. Sou muitíssimo grata ao grande encorajamento do Dr. Helion Póvoa Neto, coordenador do Núcleo Interdisciplinar de Estudos Migratórios do Rio de Janeiro (NIEM-RJ). Agradeço as inesquecíveis contribuições da Dra. Antonella Pinnelli e do Dr. Salvatore Strozza, do Departamento Demografia da Università Degli Studi “La Sapienza” em Roma, Itália. Nessa universidade, agradeço ainda o apoio administrativo de Elizabetta Egidi, Anna Frullini, Elizabetta Maglieta, Cristina Putteo e Giovanna Bianco. Finalmente, agradeço a Coordenação de Aperfeiçoamento de Pessoal de Nível Superior (CA$\mathrm{PES}$ ) pelo financiamento (processo número BEX: 0388/0303) para esta pesquisa.

** Escola Politécnica de Saúde Joaquim Venâncio - Fundação Oswaldo Cruz, Rio de Janeiro.
} 


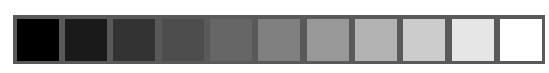

Sousa, I. C. F. A integração de imigrantes brasileiras em Roma: conquistas e dificuldades

envolva gênero na imigração transnacional, conforme já enfatizado por Sutton (1992). Essa perspectiva deve também abordar as mudanças nas condições para imigração, as quais têm recentemente deteriorado ou se restringido muito. Assim, é necessário continuar pesquisando o fortalecimento feminino especialmente em condições precárias, como as experimentadas por populações migrantes. Considerando o ponto de vista de mulheres imigrantes, mais ações sociais e melhores definições de políticas públicas poderiam ser tomadas em seu favor.

Imigração brasileira na Itália

Bogus (1995) apontava, há uma década, a Itália como um país importante de destino de brasileiros imigrantes na Europa. Os imigrantes brasileiros, como outros, experimentam dificuldades de acesso aos sistemas de ensino e de saúde, e ao mercado de trabalho. Sabe-se que muitas das barreiras sofridas por imigrantes são culturais e se originam de fatores subjetivos. Nesse sentido, Bogus e Bassanezi (2001) enfatizam que imigrantes brasileiros, documentados ou não, são alvo de preconceito e discriminação. Há muitas dificuldades sociais e barreiras culturais enfrentadas pela população imigrante. Algumas organizações não-governamentais e igrejas trabalham para apoiá-los e integrá-los. Assim, é de grande relevância analisar os dados pela perspectiva da mulher imigrante para verificar se suas ações atingem, e em que medida, as necessidades das mulheres migrantes.

Na presente ordem capitalista, os contratos de trabalhos tornam-se cada vez mais frágeis. Além disso, os benefícios de educação, saúde e previdência social estão cada vez mais ausentes, sobretudo para as populações mais fragilizadas ou mais pobres, como a dos imigrantes não documentados. Nesse contexto, é importante pesquisar os depoimentos dos imigrantes sobre suas condições de vida no novo país e no de origem.

400 
Nas nossas sociedades cada vez mais pluralistas, os pontos de vista sobre qualquer assunto tendem a se multiplicar. E se a pluralidade é imensamente rica, infelizmente também vem acompanhada de preconceito e discriminação. Aspectos culturais, como língua, hábitos de saúde, valores educacionais, comportamentos de trabalho e formas de lazer, muitas vezes se tornam pontos de discórdia. Mudanças sociais serão criadas se forem legitimadas as opiniões dos desfavorecidos, principalmente levando-se em conta que as sociedades mais justas pressupõem a participação igualitária de todos no processo decisório.

\section{Opressão da mulher e conquista de poder}

É fundamental para a construção de sociedades mais democráticas o fortalecimento das mulheres, principalmente as mais pobres. Considerando a discriminação experimentada pelas mulheres, elas são consideradas como as mais necessitadas de conquistar fortalecimento (STROMQUIST, 1993) e com mais potencial de transformar a realidade por ter visão diferente da população mais privilegiada (BLUTER citado por SLEETER, 1991). Assim, nas experiências de vida dos oprimidos, podem ser encontrados elementos potenciais de mudança do status quo, se forem utilizados estrategicamente para o seu fortalecimento. Segundo Freire (1993, p. 122-123): "A práxis revolucionária somente pode opor-se à práxis das elites dominadoras... Para dominar, o dominador não tem outro caminho senão negar às massas populares a práxis verdadeira. Negar-Ihes o direito de dizer sua palavra, de pensar certo".

Como muitas vezes o trabalho dos pobres é manipulado pelas classes dominantes, é fundamental que o fortalecimento das mulheres seja de fato emancipatório para elas. De acordo com Antrobus (1989), não é raro a questão de o fortalecimento feminino ser explorada por algumas agências internacionais com o intuito de aumentar as atribuições sociais das mulheres, e não de mudar a situação de subordinação. Por isso, Molyneux (1985) distingue a 


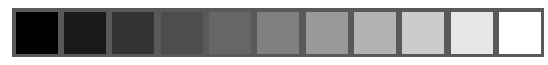

Sousa, I. C. F. A integração de imigrantes brasileiras em Roma: conquistas e dificuldades

conquista de poder feminino relativa a interesses práticos daquela referente a interesses estratégicos. Enquanto os primeiros proporcionam conhecimentos e habilidades de desenvolvimento pessoal, sem questionar a subordinação da mulher frente ao homem, os últimos buscam a paridade entre os sexos. Na conquista de poder pelas mulheres pobres, é necessário que haja a combinação de ambos os interesses.

Uma definição de fortalecimento feminino é a descrita por Stromquist (1993). A autora explica que esse fortalecimento leva mais à autoconfiança do que à confiança em intermediários, promove ações ligadas às necessidades e provoca transformações coletivas substanciais. Para Stromquist (1993), essa conquista, além de envolver identidade pessoal, estimula a reflexão sobre os direitos humanos. A autora explica que tal conquista de poder pelas mulheres pode ocorrer nas dimensões psicológica, cognitiva, econômica e política. Sendo ampla a proposta de as mulheres conquistarem fortalecimento, ela implica mudanças em várias dimensões.

\section{O foco da pesquisa e a condução do estudo}

O fortalecimento feminino foi estudado no contexto da imigração e no contexto das normas culturais e sociais do Brasil e da Itália. Esse fortalecimento é um processo multidimensional que requer mudanças individuais e institucionais (GERMAN \& ANTROBUS, 1989; STROMQUIST, 1993). Do ponto de vista social, também, há necessidades de mudanças na percepção coletiva do papel protagonista muitas vezes desempenhado pelas mulheres no processo migratório. De fato, só recentemente tem se dado visibilidade para o processo migratório feminino. O imaginário social costuma ser de que a migração feminina se dá em função da masculina. No entanto, isso nem sempre ocorre, e muitas mulheres têm um papel protagonista de escolher imigrar para países mais igualitários em termos de gênero. Por isso, Grasso (1994) distingue duas formas

402 
de migração feminina: instrumental, que é utilitária e limitada no tempo, e promocional, na qual as mulheres tentam se ajustar a uma nova sociedade por ser mais igualitária em termos de gênero e na qual elas podem se sentir mais emancipadas.

Ressalte-se que as opressões sociais podem provocar, em algumas mulheres, o movimento de migrar para dentro ou fora do país, o que necessariamente não assegura melhores condições de vida no novo local. Mesmo que as condições de vida para si ou sua família sejam melhores, haverá sempre um choque cultural e um duro processo de adaptação. Daí ser importante estudar as condições de integração no país de destino.

As questões enfocadas nas entrevistas com as mulheres imigrantes foram as referentes às atividades recentes e passadas em instituições (ensino e trabalho) bem como as relacionadas à demanda por serviços em instituições (de saúde e de documentação) no Brasil e na Itália. Foram também enfatizadas opiniões sobre instituições nos dois países, e participação em redes sociais que levaram à migração. As entrevistas eram anônimas e seguiram procedimentos éticos, considerando que tanto questões pessoais como aquelas sobre imigração poderiam causar constrangimento para as entrevistadas.

Os dados foram coletados com entrevistas orais e notas feitas durante observações nos locais selecionados de Roma. A análise baseou-se em anotações feitas sobre observações e entrevistas, recaindo o foco sobre a experiência das participantes.

A pesquisa utilizou metodologia qualitativa. O procedimento para contato foi o de "bola de neve". Os lugares selecionados para a pesquisa foram o Consulado e a Embaixada brasileiros, uma galeria de arte, uma pizzaria, duas igrejas, dois restaurantes, um bar e a Associazione delle Donne Brasiliane in Italia - ADBI (Associação de Mulheres Brasileiras na Itália). De dezembro de 2003 a agosto de 2004, 46 mulheres e 34 homens foram entrevistados, além de três pessoas-chave para a comunidade de brasileiros. As pessoas-chave contatadas foram a presidente da $\mathrm{ADBI}$, o padre trabalhando com a comunidade latino-americana e uma mulher que é Conselheira da 


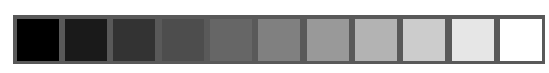

Sousa, I. C. F. A integração de imigrantes brasileiras em Roma: conquistas e dificuldades

Comunidade no Consulado Brasileiro. Foram construídos três tipos de questionários (mulheres, homens e pessoas-chave) semi-estruturados para que os temas da pesquisa alcançassem todas as participantes. A escolha das mulheres entrevistadas obedeceu aos seguintes critérios: a mulher devia ser nascida no Brasil ou com nacionalidade brasileira ter vivido a maior parte de sua vida no Brasil. Os voluntários homens nessa pesquisa também preenchiam aos mesmos critérios.

O método escolhido foi o da análise de conteúdo. Bardin (1977) cita entre as possibilidades de análise de conteúdo: a categorial, a de avaliação, a de expressão, a das relações e a do discurso. Para este trabalho, escolheu-se a categorial temática por ser a técnica de análise de conteúdo mais antiga, rápida e eficaz para aplicação a discursos diretos.

Vale lembrar que o foco desta pesquisa era as mulheres brasileiras imigrantes, buscando-se alcançar veracidade e o maior grau de representatividade do fenômeno estudado. Considera-se a pesquisa relevante não só por tratar de problemas de desenvolvimento individual e social, mas sobretudo pela possibilidade de ampliação do conhecimento na área.

A principal questão desta pesquisa é descobrir em que medida a migração contribui para o fortalecimento feminino a partir da subjetividade das mulheres entrevistadas. O estudo sobre as brasileiras imigrantes na Itália foi um importante passo para melhor compreender as questões dos imigrantes na tendência moderna de imigração, que têm levado, progressivamente, ao aumento do contingente feminino nas migrações oriundas de países periféricos.

O perfil dos brasileiros entrevistados

As mulheres entrevistadas eram provenientes de 13 diferentes estados no Brasil, e os homens eram originários de 11 estados. As mulheres tinham entre 25 a 59 anos e os homens tinham entre 19 a 54 anos. O tempo de estadia dos entrevistados em Roma variou

404 
de seis meses a 22 anos, sendo que a maioria (41) chegou nos últimos três anos (2001 a 2004). É preciso enfatizar que, do total, seis mulheres e nove homens tinham ancestrais italianos e que cinco mulheres (três por casamento e duas por ter ascendência) e quatro homens tinham a cidadania italiana na época da entrevista.

Nesta pesquisa, as mulheres foram entrevistadas em maior profundidade que os homens, resultando mais dados sobre elas. A maioria era solteira (25). Dentre as que tinham companheiros italianos, 12 eram casadas oficialmente. Das 46 mulheres entrevistadas, apenas 11 não tinham experimentado migração interna no Brasil, o que é um resultado muito interessante porque pode ser que a migração interna funcione como uma maior predisposição para imigrar para o exterior.

A maioria das mulheres (30) estudou italiano em Roma e apenas duas estudaram italiano no Brasil, demonstrando, em geral, uma ausência de preparo lingüístico e socialização antecipatória para a imigração. Esses resultados aparecem muito porque a cultura italiana é percebida como similar à brasileira. Em geral a imigração também não foi longamente planejada e houve falta de acesso a cursos de italiano.

A maior parte das entrevistadas tinha permissão legal para permanecer na Itália (33) e três esperavam documentação. No entanto, a permissão legal não necessariamente refletia a ocupação e constituía algumas vezes estratégia de permanência. Ressaltese ainda que a legalidade das mulheres casadas com italianos nem sempre propiciou facilidade de inserção no mundo do trabalho. A maior parte das mulheres tinha pelo menos segundo grau completo (39), e dessas 20 tinham diploma universitário.

\section{Inserção laboral e satisfação}

A maior parte das mulheres trabalha como doméstica, tomando conta de crianças ou servindo em restaurantes. Mais da metade declarou que estava tendo uma melhor vida profissional na Itália do 


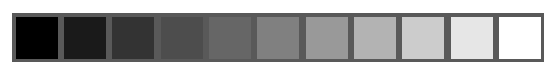

Sousa, I. C. F. A integração de imigrantes brasileiras em Roma: conquistas e dificuldades

que no Brasil. Uma questão que se coloca entre outros grupos de mulheres imigrantes vivendo de trabalho doméstico é que ele permite a estabilização da imigrante, mas pode atrapalhar a mobilidade social da mulher (NATALE; STROZZA, 1997). As formas de trabalho doméstico são percebidas diferentemente pelas mulheres entrevistadas. $O$ trabalho como diarista ou em restaurante é percebido como gerando mais autonomia para a mulher do que aquele em que a mulher tem que dormir na casa da patroa. No entanto, alugar uma vaga ou apartamento aumenta os custos financeiros e isto pode acarretar outro tipo de falta de autonomia.

A satisfação com o emprego depende do trabalho realizado anteriormente no Brasil e com o grau de escolaridade. Em geral, quanto maior a escolaridade e o nível de emprego realizado no Brasil, menos a mulher migrante mostrou contentamento em assumir posições consideradas socialmente inferiores ainda que recebendo financeiramente mais por elas na Itália. Claramente, ganhar melhor na Itália era um dos fatores de satisfação, mas principalmente para as que já desempenhavam o mesmo trabalho no Brasil. A satisfação também dependia da perspectiva de trabalho no Brasil ou falta dele. Assim, se elas estavam desempregadas no Brasil antes do processo migratório, isso costumava gerar mais satisfação com o trabalho desempenhado em Roma do que se elas já se encontravam empregadas. Além disso, o tempo de estada na Itália era importante, visto que as que tinham maiores ambições profissionais esperavam com o tempo estarem inseridas no mercado. Destaca-se ainda que as mulheres imigrantes há mais tempo na Itália achavam que as recém-chegadas inflacionavam o mercado de trabalho. Em contraponto, as antigas eram percebidas com muito mais oportunidades de trabalho pelas recém-chegadas.

\section{Atividades fora de casa e do trabalho}

Foi analisada a participação das mulheres em atividades fora de casa e do trabalho. A maioria (30) participa de atividades religiosas.

406 
O papel da socialização das igrejas é importantíssimo. Nas horas de lazer, a maioria vai à Igreja. Neste estudo, foi enfatizado em duas entrevistas que a participação na Igreja Católica em Roma tomou uma proporção muito maior que a no Brasil e se devia ao fato de se sentirem sozinhas e com necessidade de socializar. Vale lembrar que algumas não participam apenas de ritos religiosas mas também de cursos gratuitos de língua de italiano e de celebrações. A igreja acaba proporcionando oportunidades de socialização e dicas de emprego e moradia. Em alguns casos, foi também reportado que receberam apoio psicológico e ajuda para arranjar empregos, resolver documentação e informação sobre serviços de saúde. $O$ padre, uma das pessoas-chaves da comunidade, também disse numa missa ter assistido ao retorno de brasileiros que não estavam adaptados na Itália. Embora possam ser muitos os benefícios que associações religiosas proporcionam aos imigrantes, os limites são reconhecidos por algumas brasileiras comentando que a Igreja não pode proporcionar aos imigrantes o que eles mais precisam, que é a documentação. Similarmente em outra pesquisa nos Estados Unidos, Zarembka's (2004) comenta que as igrejas tendem a ser as primeiras instituições procuradas pelos imigrantes, pelo simples fato de estarem abertas aos domingos.

Algumas mulheres fundaram a Associazione Delle Donne Brasiliane in Italia - ADBI. Essa associação tem objetivos e metas extremamente relevantes, como o acompanhamento de mulhere brasileiras no seu processo de adaptação e o ensino da língua portuguesa para filhos de brasileiros e adotados brasileiros. Apesar de sua relevância, a ADBI funciona precariamente, contando com a colaboração voluntária de algumas mulheres e financiamentos esporádicos. Portanto, a maioria das mulheres necessitadas não pode beneficiar-se desse primoroso trabalho. Dentre as entrevistadas, apenas três fazem parte da associação, e elas tinham diploma universitário. Considerando que ao diploma é atribuído um nível maior de conscientização e busca pelos direitos, infelizmente a ADBI pode não estar ajudando justamente as mais necessitadas. 


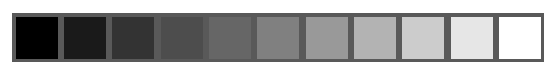

Sousa, I. C. F. A integração de imigrantes brasileiras em Roma: conquistas e dificuldades

\section{Integração social e solidão}

Talvez um dos maiores problemas para a integração social das mulheres seja sua solidão. Ganhos e perdas do processo migratório são muitas vezes relatados nas entrevistas. Em termos de perda, por exemplo, uma moça de 37 anos me disse: "Tem sido difícil para eu arranjar um namorado e quero me casar". Embora a maioria das entrevistadas estivesse em idade reprodutiva e poucas tivessem filhos, não fica claro até que ponto a migração influencia suas perspectivas de casamento e maternidade.

É importante enfatizar que uma das forças para superar a solidão parece se originar justamente dos benefícios concretos percebidos como sendo oferecidos pela sociedade que as acolhe, como a previdência social e os serviços de saúde. Uma mulher de 44 anos me contou chorando: "Eu quero envelhecer na Itália porque tenho certeza de que, se me tornar legal, terei mais benefícios sociais aqui do que no Brasil, mas eu morro de saudades dos meus netos".

Mesmo quando as mulheres são casadas, elas também sofrem de solidão. Uma mulher de 35 anos, casada com um italiano e com cidadania italiana, disse: "Eu de vez em quando me sinto tão deprimida aqui e vejo que muitas brasileiras casadas aqui em Roma se sentem do mesmo jeito. Eu não tenho autonomia porque moro com os meus sogros".

Outros problemas experimentados pelas mulheres brasileiras na Itália incluem abuso moral e físico, interferência da sogra, mulheres querendo voltar, mas com medo de perder a guarda dos filhos, italianos ameaçando revelar para as autoridades que as mulheres eram prostitutas, legalidade de trabalho apenas para o serviço doméstico, defasagem entre expectativa de trabalho e oportunidades reais.

Embora os problemas possam ser diferentes, a integração social das imigrantes não é nunca um processo fácil. De algum modo, para muitas, a força de continuar na Itália parece se ancorar paradoxalmente e de algum modo na necessidade simbólica de manter rela- 
ções com o país de origem. Constantes telefonemas para o Brasil, desenvolvimento de amizades com brasileiros na Itália e envio de remessas são sinais de investimentos de diversas naturezas (psicológico, social e material) no país de origem.

\section{Integração social, fortalecimento feminino e projeto de retorno}

Em termos de ganhos de viver na sociedade que as abriga, há muitos que podem ser contabilizadas: o emprego, o maior salário e poder aquisitivo, amizades novas, o conhecimento da cultura italiana, benefícios sociais e a possibilidade de viver em uma sociedade em que o fortalecimento feminino pode ser maior. Inesperado como resultado desta pesquisa foi a preferência, em alguns casos, pelo sistema de saúde brasileiro. Embora a maioria faça uso do sistema público de saúde italiano, algumas planejam vir ao Brasil para se cuidar mesmo tendo todas as condições legais e econômicas de se tratar na Itália. O único caso em que o tratamento é mais econômico no Brasil parece ser o dentário. No mais, não parece fazer muita diferença do ponto de vista econômico se cuidar na Itália ou no Brasil. O atendimento de saúde parece ser preferido no país de origem por um sentimento inicial de proteção e de familariedade com os profissionais brasileiros.

As mulheres imigrantes estudadas foram todas protagonistas no processo migratório. Mesmo em casos de casamento, o processo migratório começou antes do casamento visto que elas já estavam na Itália como estudantes ou trabalhadoras. Grasso (1994) declara que algumas mulheres pertencem a grupos que migram sozinhas ou com seus filhos, e que elas não podem ser vistas no caso clássico de reunião familiar. As mulheres não assumiram papéis secundários no processo. A própria decisão para migrar não apareceu por uma pressão familiar no sentido clássico. No entanto, algumas se sentem obrigadas a enviar o dinheiro ao Brasil para seus familiares e pensam pouco em si mesmas. Como diz uma entrevistada: 


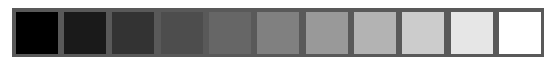

Sousa, I. C. F. A integração de imigrantes brasileiras em Roma: conquistas e dificuldades

Eu não fiz universidade no Brasil porque fiquei desempregada e não podia ajudar a família e pagar as mensalidades. Eu deveria ser mais egoísta porque meu sonho era estudar. Eu não sei ser diferente. Agora, meu pai está doente, eu ainda não estudo e mando dinheiro, porque ele não tem ajuda governamental para seus medicamentos.

Ressalte-se que, para algumas mulheres entrevistadas, o processo migratório parece apenas instrumental conforme a definição de Grasso (1994), em que essa forma de viver o processo migratório é utilitária e limitada no tempo. Assim, as mulheres esperam economizar na Itália e retornar ao Brasil para nele gozar uma vida melhor ou se beneficiar do que é de bom nas duas sociedades e ficar na que for mais conveniente.

No entanto, para algumas entrevistadas mulheres, o processo migratório parece de fato promocional segundo a definição de Grasso (1994), visto as mulheres entrevistadas buscarem se ajustar a Itália por perceber que o país é mais igualitário em termos de gênero. Algumas entrevistadas relataram a autonomia conquistada em termos de gênero, seja pelo maior poder aquisitivo e decisório seja pelos ganhos psicológicos e relacionais seja ainda pelo engajamento em mudanças sociais na área de gênero.

Enfatiza-se que o projeto de retorno para o Brasil de modo algum significa que elas não estão socialmente integradas ou tendo experimentado uma experiência apenas instrumental de imigração. $\mathrm{Na}$ amostra estudada, metade indicou a vontade de retornar ao país de origem depois de alguns anos. Mas, estudando caso a caso, uma complexidade emerge. Muitas percebiam ter uma boa integração social e mesmo assim ser seu destino o retorno ao país. Desse modo, a autopercepção de integração social é um conceito que pode apenas refletir o que é sentir-se adaptada. Por exemplo, uma mulher se definiu como bem integrada por ter um emprego, mesmo nunca tendo tempo para cultivar amizades e se relacionar amorosamente. Em contraste, algumas tinham vivenciado uma experiência de migração boa integração social e acabaram tendo futuros projetos de retorno por circunstâncias da vida. Um caso 


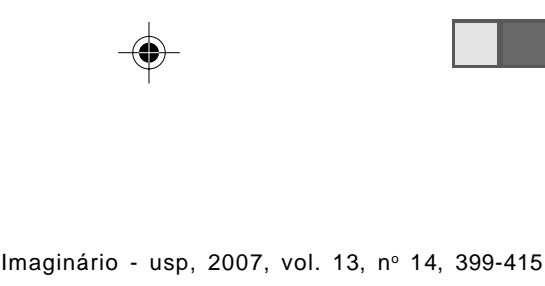

Imaginário - usp, 2007, vol. 13, n 14, 399-415

desses é de uma mulher que, tendo vivido muitos anos na Itália, dona de um bar e casada com um italiano, resolveu retornar ao Brasil com o marido para iniciar outro negócio. Assim, é importante considerar que o projeto de retorno ao país de origem nem sempre é coincidente com o grau de integração social e depende de muitas circunstâncias para desencadear de fato sua realização.

Finalmente, este estudo indica que apesar de serem muitas as dificuldades experimentadas pelas mulheres, muitas se sentem fortalecidas por suas conquistas psicológicas, sociais, culturais e ou materiais advindas do processo migratório.

Resumo: Este estudo enfatiza a integração de imigrantes brasileiras em Roma. A pesquisa se ancora teoricamente na perspectiva das relações de gênero priorizando o fortalecimento feminino e a maior visibilidade das mulheres no processo migratório. Valendo-se da metodologia qualitativa, foram tomadas notas nos locais de encontro e realizadas 83 entrevistas (mulheres, homens e pessoas-chaves para a comunidade brasileira). A análise de conteúdo revelou que a integração social ocorreu para muitas mulheres e que a solidão para elas também é um dos maiores sofrimentos. Enfatiza-se que um maior grau de integração social não necessariamente significa para essas mulheres o desejo de permanecer para sempre na Itália. A satisfação das mulheres com o emprego depende do trabalho realizado anteriormente no Brasil e com o grau de escolaridade. Apesar de serem muitas as dificuldades por elas experimentadas, muitas se sentem fortalecidas por suas conquistas psicológicas, sociais, culturais e materiais em Roma. Ressalte-se que, se para algumas mulheres o processo migratório é apenas instrumental, para outras é promocional resultando na emancipação feminina.

Palavras-chave: imigração, mulheres brasileiras, Roma. 


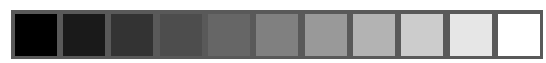

Sousa, I. C. F. A integração de imigrantes brasileiras em Roma: conquistas e dificuldades

\begin{abstract}
This study focuses on the integration of Brazilian immigrant women in Rome. The research is theoretically anchored in the perspective of gender relations giving priority to the feminine empowerment and the biggest visibility of women in the migratory process. Using a qualitative methodology approach, this research was conducted with fieldwork notes taken at local sites and 83 interviews (women, men and people representing keys roles in the Brazilian community). The content analysis disclosed that the social integration occurred for many of them but that solitude is also one of their biggest torments. It is emphasized that a bigger degree of social integration does not necessarily mean for such women the desire to remain forever in Italy. The women's satisfaction with the job depends on the work previously carried out in Brazil and on their level of education. Despite the many difficulties experienced by them, many of those women feel fortified by their psychological, social, cultural and material conquests in Rome. Note that, if for some women the migratory process is only instrumental, for others it is promotional and results in women's emancipation.
\end{abstract}

Key words: immigration, Brazilian women, Rome.

Resumen: Este estudio enfatiza la integración de inmigrantes brasileñas en Roma. El marco teórico de la investigación tiene como base la perspectiva de las relaciones de género priorizando el fortalecimiento femenino y la visibilidad de mujeres en el proceso migratorio. Usando metodología cualitativa, esta investigación fue conducida con notas de campo y 83 entrevistas (mujeres, hombres y personas-claves para la comunidad brasileña). El análisis del contenido reveló que la integración social sucedió para muchas mujeres y que la soledad es uno de los sufrimientos más grandes. Se acentúa que un mayor grado de integración social no significa, necesariamente, para las mujeres el deseo de permanecer en 
Italia. La satisfacción de las mujeres con el trabajo depende del trabajo realizado en Brasil y con el nivel de estudio. A pesar de que muchas mujeres experimentaron dificultades, otras se sentían fortificadas por sus conquistas psicológicas, sociales, culturales y materiales en Roma. Cabe destacar que si para algunas mujeres el proceso migratorio es solamente instrumental, para otras es promocional alcanzando la emancipación femenina.

Palabras clave: Roma, método cualitativo, inmigrantes brasileñas.

Bibliografia

ALI, J. Mental health of Canada's immigrants. In: Supplemental to Health Reports (Statistics Canada, Catalogue 82-003), n. 13, p. 111, 2002.

ANTROBUS, P. The empowerment of women. In: GALLIN, R. S.; ARONOFF, M. \& FERGUSON, A. (Orgs.), The women and international development annual. San Francisco: Westview Press. 1989. p. 189207.

BARDIN, L. Análise de conteúdo. São Paulo: Edições 70, 1977.

BASSANEZI, M. S. C. B.; BOGUS, L. M. M. Brasileiros na Itália. Movimentos migratórios e inserção social. In: Trabalho apresentado no XXII Encontro da ANPOCS, Grupo de Trabalho 09: Migrações Internacionais, 1998. Caxambu, MG. Brazil. Disponível em http:// www.clasecol.edu.ar/ libros/anpocs/bassan.rtf. (Data de acesso: 20 jan. 2003).

BOGUS, L. M. M. Migrantes brasileiros na Europa Ocidental: uma abordagem preliminar. In: Patarra, Neide L. (Org.). Emigração e imigração internacionais no Brasil contemporâneo. Programa Interinstitucional. Campinas, SP, p.111-121, 1995. 


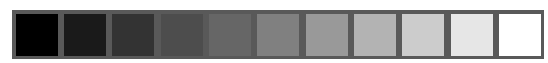

Sousa, I. C. F. A integração de imigrantes brasileiras em Roma: conquistas e dificuldades

; BASSANEZI, M. S. C. B. Brasileiros (as) na Itália: Nuovi Citadini ou Extracomunitari? In: CASTRO, Maria G. (Org). Migrações Internacionais: Contribuições para políticas. Brasília: CNPD. p. 409-425, 2001.

FREIRE, P. Pedagogia do oprimido. ed. 22. Rio de Janeiro: Paz e Terra, 1993.

GERMAIN, A.; ANTROBUS, P. New partnerships in reproductive health care. Populi, n.16: p.18-30, 1989.

GRASSO, M. Donne senza confini. Immigrate in Italia tra marginalità ed emancipazione. Torino: L' Hartmann Italia, 1994.

MOLYNEUX, M. Mobilization without emancipation? Women's interests, the state and revolution in Nicaragua. In: Feminists Studies. n.11, p. 227-254. 1985.

MONKMAN, K. Transnational migration and learning processes of Mexican adults constructing lives in California. In: International Journal of Education Development. n.19, p. 367-382, 1999.

NATALE, M.; STROZZA, S. Gli immigrati stranieri in Italia. Quanti sono, chi sono, come vivono? Cacucci Editore, Bari, 1997.

OGBU, J. U. Variability in minority responses to schooling: Nonimmigrants Vs. Immigrants. In: SPINDLER, George and SPINDLER, Louise (eds.). Interpretive ethnography of education at home and abroad. New Jersey, Lawrence Erlbaum Associates, p. 255-280, 1987.

PÉREZ, C. E. Health status and health behavior among immigrants. In: Supplemental to Health Reports (Statistics Canada, Catalogue 82003). n.13, p. 1-12, 2002.

SCHILLER, N. G.; BASCH, L.; BLANC-SZANTON, C. Transnationalism: A new analytical framework for understanding migration. In: $\mathrm{SCH}$ LLER, N. G.; BASCH, L.; BLANC-SZANTON, C. (eds.). Towards a transnational perspective on migration. Race, class Ethnicity, and nationalism reconsidered. Annals of the New Academic of Sciences, New York. V. 645, p. 1-24, 1992.

SLEETER, C. E. (Org). Empowerment through multicultural education. Albany: State University of New York, 1991.

STROMQUIST, N. The theoretical and practical bases for empowerment. Revised version of a paper presented at the International Seminar on Women's Education and Empowerment, organized by the UNESCO - Institute for Education, Hamburg. 22 p., 1993. 
SUTTON, C. Some thoughts on gendering and internationalizing our thinking about transnational migrations. In: SCHILLER, N. G.; BAS$\mathrm{CH}, \mathrm{L}$.; BLANC-SZANTON, C. (eds.). Towards a transnational perspective on migration. Race, class Ethnicity, and nationalism reconsidered. Annals of the New Academic of Sciences. New York. V. 645, p. 241-249, 1992.

ZAREMBKA, J. M. Panni sporchi d' America: domestiche migranti e nuove schiavitu. In: EHRENREICH, B.; HOSCHSCHILD, A. R. Donne globali. Tate, colf e badanti. p. 145-157. (Valeria Bellazzi e Antonio Bellommi, Trans.). Milano: Feltrinelli, 2004.

e-mails: isabela_felix@yahoo.it / isabelacabral@fiocruz.br Recebido em 11/09/2006. Aceito em 15/09/2006. 


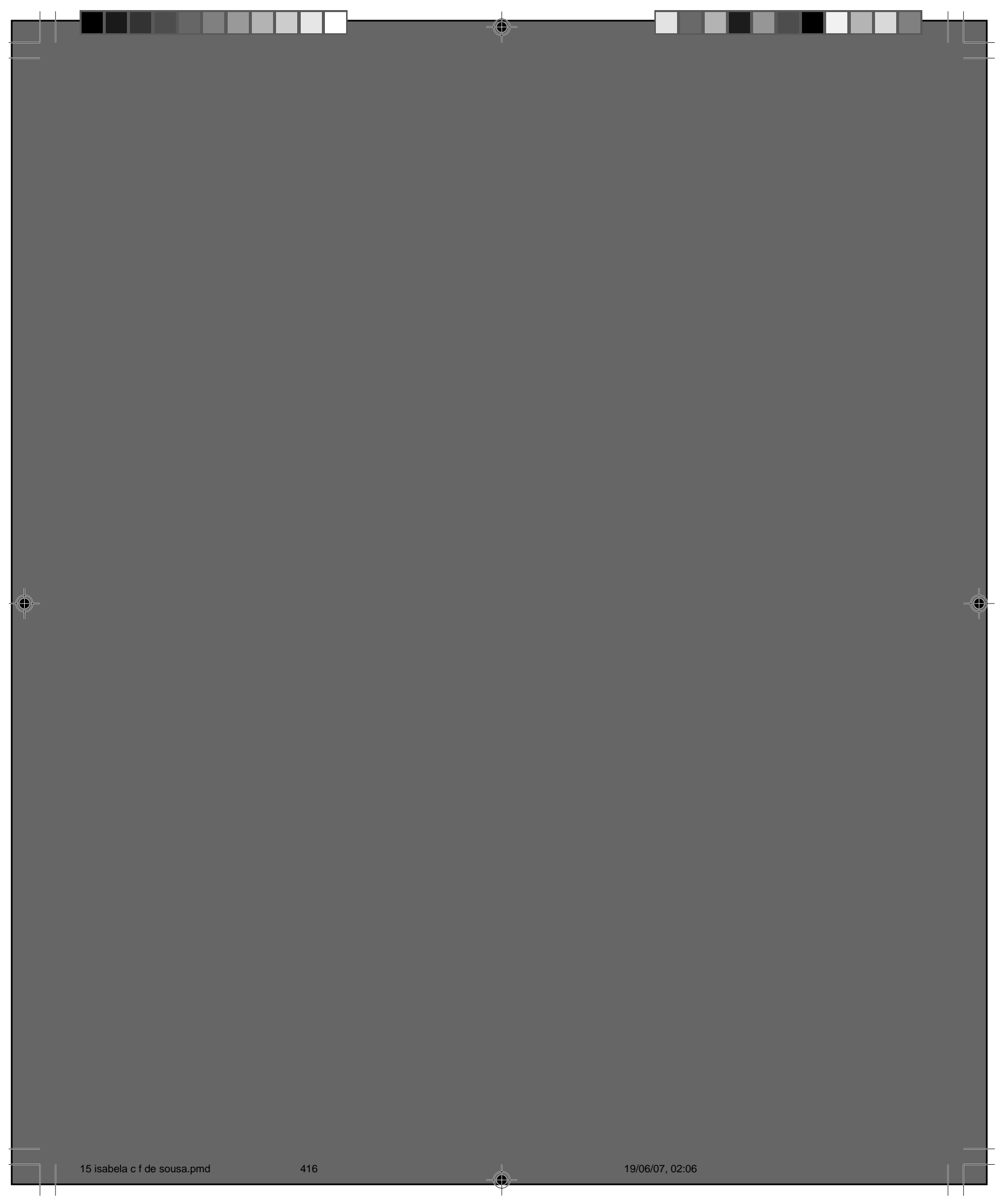

